\title{
Article
}

\section{Freeze-Drying Ethylcellulose Microparticles Loaded with Etoposide for In Vitro Fast Dissolution and In Vitro Cytotoxicity against Cancer Cell Types, MCF-7 and Caco-2}

\author{
Ahmed A. H. Abdellatif ${ }^{1,2, *} \mathbb{0}$, Mashari A. Aldhafeeri ${ }^{1}$, Waleed H. Alharbi ${ }^{1}$, Fahad H. Alharbi ${ }^{1}$, \\ Waleed Almutiri ${ }^{1}$, Mohammed A. Amin ${ }^{1,2}$, Mohammed F. Aldawsari ${ }^{3}(1)$ and Hamzah M. Maswadeh ${ }^{1, *}(\mathbb{D}$ \\ 1 Department of Pharmaceutics, College of Pharmacy, Qassim University, Buraydah 51452, Saudi Arabia; \\ mshari737@gmail.com (M.A.A.); waleedalsalhi93@gmail.com (W.H.A.); Fhd.h.alharbi@gmail.com (F.H.A.); \\ Phd.mutiri@hotmail.com (W.A.); m.darwish@qu.edu.sa (M.A.A.) \\ 2 Department of Pharmaceutics and Industrial Pharmacy, Faculty of Pharmacy, Al-Azhar University, \\ Assiut 71524, Egypt \\ 3 Department of Pharmaceutics, College of Pharmacy, Prince Sattam Bin Abdulaziz University, \\ Al-Kharj 11942, Saudi Arabia; moh.aldawsari@psau.edu.sa \\ * Correspondence: a.abdellatif@qu.edu.sa (A.A.H.A.); msodh@qu.edu.sa (H.M.M.)
}

Citation: Abdellatif, A.A.H.; Aldhafeeri, M.A.; Alharbi, W.H.; Alharbi, F.H.; Almutiri, W.; Amin, M.A.; Aldawsari, M.F.; Maswadeh, H.M. Freeze-Drying Ethylcellulose Microparticles Loaded with Etoposide for In Vitro Fast Dissolution and In Vitro Cytotoxicity against Cancer Cell Types, MCF-7 and Caco-2. Appl. Sci. 2021, 11, 9066. https://doi.org/10.3390/ app11199066

Academic Editor: Maria Stefania Sinicropi

Received: 16 August 2021

Accepted: 25 September 2021

Published: 29 September 2021

Publisher's Note: MDPI stays neutral with regard to jurisdictional claims in published maps and institutional affiliations.

Copyright: (C) 2021 by the authors Licensee MDPI, Basel, Switzerland This article is an open access article distributed under the terms and conditions of the Creative Commons Attribution (CC BY) license (https:/ creativecommons.org/licenses/by/ $4.0 /)$.

\begin{abstract}
The aim of this study was to improve the solubility of etoposide-ethylcellulose (ET-ETO) microparticles using the freeze-drying technique. Ethylcellulose (EC) microparticles loaded with etoposide (ETO) were prepared with different drug-polymer molar ratios of 1:1, 1:3, 1:6, and 1:20 by the solvent evaporation method. The size of the prepared microparticles was $0.088 \mu \mathrm{m}$. The results showed that the amount of ETO encapsulated into the microparticles was 387.3, 365.0, 350.0, and $250 \mu \mathrm{g} / 50 \mathrm{mg}$ microparticles for microparticles with drug-polymer ratios of 1:1, 1:3, 1:6, and 1:20, respectively. The FT-IR spectra showed no chemical interaction between ETO and the polymer in the solid state. The results obtained from the dissolution experiment showed that the freeze-

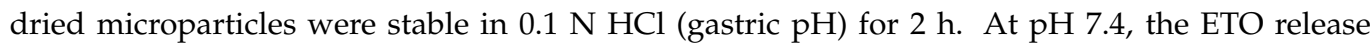
was 60 to $70 \%$ within the first $15 \mathrm{~min}$ and approximately $100 \%$ within $30 \mathrm{~min}$. Results from the application of different dissolution models showed that the equations that best fit the dissolution data for the ET-ETO microparticles at pH 7.4 were the Higuchi and Peppas model equations. The in vitro cytotoxicity assay of free ETO and freeze-dried microspheres prepared in this study with a drug-polymer ratio of 1:1 was performed in two mammalian cancer cell lines, MCF-7 (for bone cancer of the mammary organ) and Caco-2 (for mammalian epithelial colorectal adenocarcinoma). The results showed that the half-maximal inhibitory concentrations (IC50 values) for ETO and freezedried ET-ETO microparticles were $18.6 \mu \mathrm{M}$ and $27.1 \mu \mathrm{M}$, respectively. In conclusion, freeze-dried ET-ETO is a promising formulation for developing a fast-dissolving form of ETO with a significant antiproliferative activity against the tested cell lines used in this study. It is a promising formulation for local duodenal area targeting.
\end{abstract}

Keywords: etoposide; freeze-drying; targeted delivery; ethylcellulose; polymer microparticles

\section{Introduction}

Etoposide (ETO semisynthetic podophyllotoxin derivative, with a molecular formula of $\mathrm{C}_{29} \mathrm{H}_{32} \mathrm{O}_{13}$ ) has an anticancer activity used for treating various tumours, such as lymphoma, small cell lung cancer, and leukaemia. Etoposide is classified as class IV in the Biopharmaceutics Classification System (BCS) with insufficient aqueous solubility and permeability, making etoposide a poor candidate for oral administration, resulting in many formulations of etoposide being prepared as injections. However, the injectable formulations of etoposide contain high quantities of organic solvents as well as surfactants, which may produce allergic reactions in patients $[1,2]$. Therefore, the development of oral 
preparations of etoposide has become an attractive research field. To facilitate the oral absorption of ETO, several strategies have been adopted, including nanostructured lipid carriers (liposomes) and polymeric nanoparticles. Several techniques have been reported in previous studies to enhance the solubility of poorly soluble drugs. One of these techniques is freeze-drying. Freeze-drying has been used to improve drug solubility in numerous solid oral dosage forms, such as solid dispersions of powders, tablets, capsules, and microparticles. Freeze-dried powders have potential applications for the delivery of potent drugs. The preparation of microparticles involves freeze-drying for pharmaceutical formulations that produce highly porous microparticles with a low density that are more fragile [1] Upon freeze-drying, the formed microparticles exhibit plastic flow in the glass transition region at room temperature [2]. The freeze-drying technique is expected to reduce the number of particles and produce spherical particles with comparatively large geometric diameters and low particle mass densities [3]. Using a dual emulsion-solvent evaporation technique, Ungaro et al. produced gas-powered, large, porous, polymer-centred (LPGA) polymers [4].

Moghaddam et al. improved the solubility and dissolution activity of the poorly water-soluble compound raloxifene hydrochloride ( $\mathrm{RH})$. Moghaddam et al. utilized the spray freeze-drying (SFD) technique and used polyvinyl pyrrolidone or hydroxypropyl beta-cyclodextrin as coating products [5]. Nogueira et al. showed that freeze-dried microencapsulated blackberry pulp powders displayed enhanced solubility in water, while the antioxidant ability of the blackberries improved in comparison to that of blank particles, indicating good potential as a medium to release bioactive compounds into feed [6]. Cherng et al. studied a frieze-dried poly((2-dimethylamino)-ethyl methacrylate)-loaded transfected plasmid, showing an excellent method to preserve the size and transfection potential of polymer/plasmid complexes. Additionally, this polymer showed fast release of the plasmid to the target site [7]. These observations suggest that hollow or porous spherical particles with internal structures have significantly improved solubility compared with standard mechanically micronized crystalline particles. Throughout this work, we asked whether ET-ETO could be generated as shrunken, more soluble, partly collapsed particles that would be appropriate for use in GIT targeting through the freeze-drying technique of the formed micronized ET-ETO. This would contribute to a higher density of particles, stronger GIT transfer, and lower mechanical fragility.

Ethylcellulose (EC) is a polymer that is biocompatible with many types of drugs and is characterized as $\mathrm{pH}$-dependent with a high solubility at $\mathrm{pH}$ 7.4. EC is a suitable polymer for loading acid-sensitive drugs or drugs that harm the stomach. ETO-coated EC can be used as a colon-specific therapy for colorectal cancer because it can easily be dissolved in $\mathrm{pH} 7.4$ [8,9]. Moreover, the formulated freeze-dried EC microparticles showed enhanced dissolution and improved solubility at $\mathrm{pH}$ 7.4. The dissolution of freeze-dried items is rapid because of their large porosity and low-density surface area [10]. As drug delivery systems, microparticles have improved the efficiency of various drugs due to their advantages, which include (1) increasing drug solubility, (2) delivering the drug to a specific area, (3) controlling the rate of drug release, and (4) protecting bioactive drugs from acidic degradation [11].

This study aimed to improve the solubility of ET-ETO microparticles using the freezedrying technique. Microparticles composed of EC containing ETO were prepared by the solvent evaporation method to enhance the solubility of ETO and to maximize the amount of drug release at $\mathrm{pH} 7.4$ simulated to the duodenal area. The dissolution kinetic of prepared microparticles was studied using five models and the in vitro cytotoxicity assay of free ETO and freeze-dried microspheres was performed in two mammalian cancer cell lines, MCF-7 (for bone cancer of the mammary organ) and Caco-2 (for mammalian epithelial colorectal adenocarcinoma). 


\section{Materials and Methods}

\subsection{Materials}

Etoposide powder was purchased from Boots Co., Nottingham, UK. Ethylcellulose was purchased from Sigma Chemical Co., California, CA, USA. Methylcellulose was purchased from Dow Chemical Fluka, Greifensee, Switzerland. Potassium chloride, hydrochloric acid, sodium hydroxide, acetic acid, and potassium dihydrogen orthophosphate were purchased from El-Nasr Pharmaceutical Chemical Co., Abu-Zaabal, Cairo, Egypt. All chemicals were of analytical grade. The mammary gland breast cancer cell line (MCF-7), and human mammalian epithelial colorectal adenocarcinoma (Caco-2) were purchased from the American Type Culture Collection (ATCC \#ATCC ${ }^{\circledR} 30-4500 K^{\mathrm{TM}}$, Middlesex, UK).

\subsection{Methods}

\subsubsection{Preparation of Microparticle-Loaded Etoposide}

The preparation of EC microparticles loaded with ETO proceeded according to the previously reported method by Mohammed et al., with few modifications [8]. In detail, EC and ETO with different molar ratios of 1:1, 1:3, 1:6, and 1:20 were dissolved in a mixture of chloroform/methanol (1:1). The prepared ET-ETO mixture was added dropwise into $20 \mathrm{~mL}$ of $0.05 \%$ methylcellulose (MC) aqueous solution with stirring using a mechanical homogenizer at 10,000 rpm for $1 \mathrm{~h}$. The emulsion was stirred at room temperature until the organic phase evaporated. The formed microparticles of ET-ETO were filtered, washed, and then dried by freeze-drying or oven-drying for further investigation (Figure 1). The microparticles dried in the oven were maintained at $40^{\circ} \mathrm{C}$ for $4 \mathrm{~h}$.

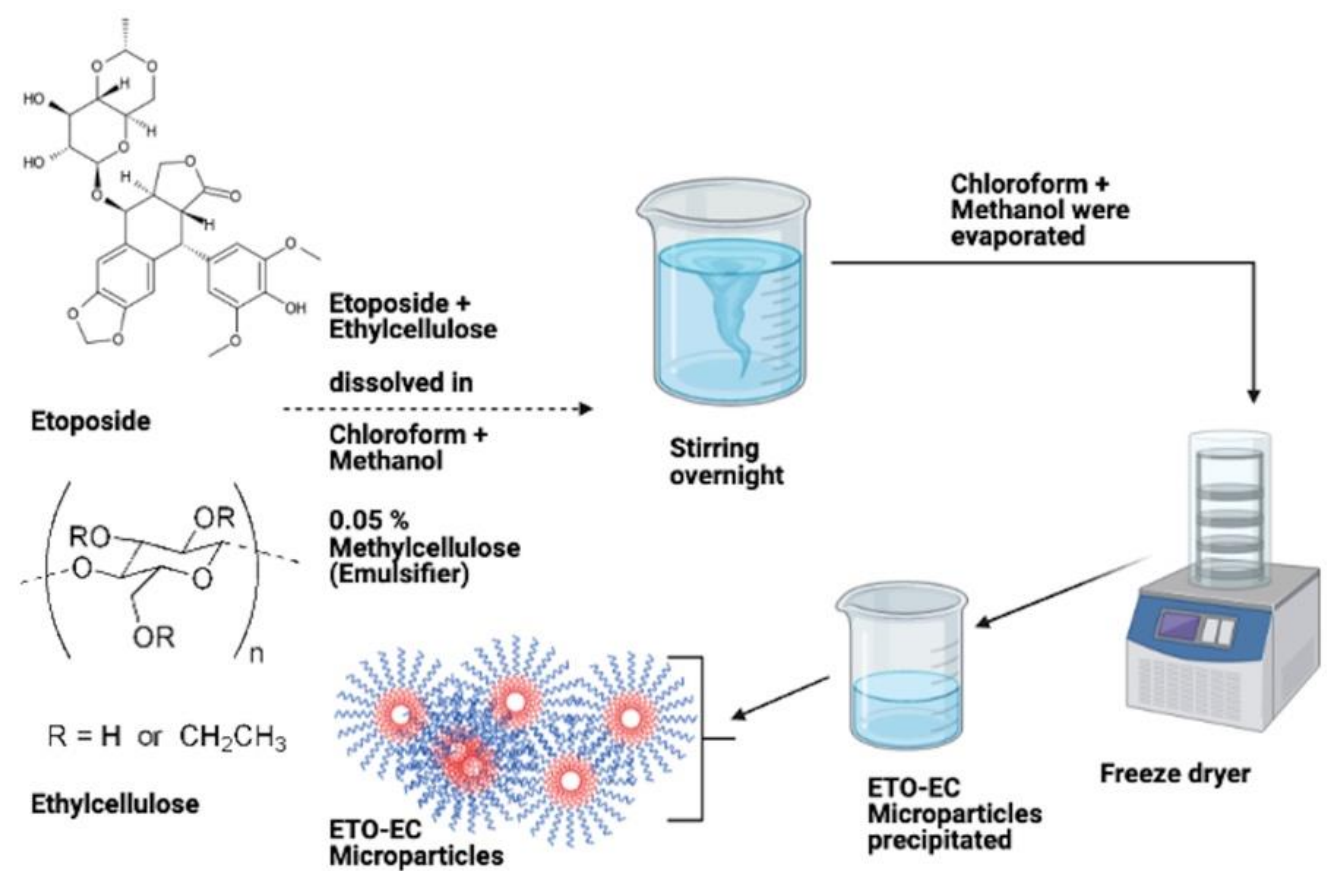

Figure 1. Schematic diagram representing the process of ethylcellulose microparticle formation loaded with ETO.

Freeze-drying was achieved by drying the original dispersion of aqueous EC-ETO in a freeze-dryer (Christ GmbH, Osterode, Germany). Drying occurred at $-20{ }^{\circ} \mathrm{C}$ for $24 \mathrm{~h}$, and the post-drying temperature was $20^{\circ} \mathrm{C}$ for $4 \mathrm{~h}$. A cake of coated EC-ETO, which was gently broken into a flowable powder with a mortar and pestle, was obtained after freeze-drying. The polymer powder was stored in the desiccator to prevent moisture absorption [12]. 


\subsubsection{Characterization of the Prepared Ethylcellulose Microparticles Loaded with ETO}

The size diameter of the prepared microparticles was measured using a laser particle size analyser (SLAD-400 from Shimadzu, Japan), and their morphology was investigated. For SEM preparation, $5 \mathrm{mg}$ of each primary dried ET-ETO and freeze dried ET-ETO were crushed into a fine powder using a mortar and pestle. Double-sided copper conductive tape was used to cover the surface of the double-sided copper conductive tape with randomly selected particle powder samples. Afterwards, the particles were sputter-coated using a sputter coater (JOEL JFC-1300) with a thin layer of platinum in a vacuum for $55 \mathrm{~s}$ at $25 \mathrm{~m} \AA$ using a coating unit in order to make them electrically conductive before being imaged in an SEM. The SEM was performed on a JEOL JSM-550 Scanning Electron Microscope (Jeol, Akishima, Tokyo, Japan) to investigate the surface morphology of the particles [13,14].

\subsubsection{Determination of ETO Drug Content in the Ethylcellulose Microparticles}

To determine the percentage of entrapment efficiency (\% EE) of ETO in the EC microparticles, an amount equivalent to $2 \mathrm{mg}$ of ETO was dissolved in $1 \mathrm{~mL}$ of $\mathrm{CHCl}_{3} /$ methanol. After complete dissolution, $4 \mathrm{~mL}$ of Sorensen phosphate buffer at $\mathrm{pH} 7.4$ was added to the $\mathrm{CHCl}_{3}$ solution, and the mixture was stirred by a magnetic stirrer at room temperature until the $\mathrm{CHCl}_{3} /$ methanol odour completely disappeared. The solution was then filtered and diluted to $5 \mathrm{~mL}$ in a volumetric flask with a phosphate buffer solution. One millilitre of this solution was diluted with the phosphate buffer to $25 \mathrm{~mL}$ in a volumetric flask. The ETO content of the solution was then analysed spectrophotometrically at $317 \mathrm{~nm}$ using a UV/Vis spectrophotometer (Ultraviolet double beam Spectrophotometer 1601, Shimadzu, Japan) against a blank solution that was prepared in the same manner using empty microparticles $[9,15,16]$.

\subsubsection{Fourier Transform Infrared Spectroscopy (FT-IR)}

Fourier transform infrared spectroscopy (FT-IR) (BRUKER, OPTIK GmbH, Germany) was used to study the compatibility of EC with ETO by comparing the spectra showing the functional groups for both ingredients before and after the preparation of the microparticles. The FT-IR spectra were collected from 4000 to $400 \mathrm{~cm}^{-1}$ [17-21].

\subsection{Physical Stability}

Physical stability was tested by the storage of the prepared microparticles for two months at $25^{\circ} \mathrm{C}$ and $4{ }^{\circ} \mathrm{C}$ [22]. Physical characteristics such as colour, shape, particle size diameter, and drug content were evaluated before and after storage to confirm the stability of the prepared microparticles.

\subsection{In Vitro Release Study of the Ethylcellulose Microparticles Loaded with ETO}

An in vitro release study for all prepared formulations of EC before and after freezedrying the microparticles was conducted for $2 \mathrm{~h}$ in $0.1 \mathrm{~N} \mathrm{HCl}(\mathrm{pH} 1.2)$ and phosphate buffer ( $\mathrm{pH}$ 7.4) for $10 \mathrm{~h}$ by using a basket dissolution apparatus (Validata-Hansen Research Chatsworth, California, CA, USA). The dissolution apparatus was adjusted according to the BP requirement of appendix XII B (MHRA, 2014b). An accurately weighed quantity of EC microparticles equivalent to $50 \mathrm{mg}$ of ETO was placed in the basket of the dissolution apparatus. The volume of dissolution medium used was $900 \mathrm{~mL}$, the temperature of the dissolution medium was controlled at $37 \pm 0.5^{\circ} \mathrm{C}$, and the stirring speed was maintained at $50 \mathrm{rpm}$. Samples were withdrawn at predetermined time intervals and immediately replaced with an equal volume of fresh buffer. Samples were filtered, and the concentration of free ETO was determined at $317 \mathrm{~nm}$ using a UV/Vis spectrophotometer [8,9].

\subsection{Cytotoxicity Assay}

An in vitro cytotoxicity assay of free ETO and freeze-dried microspheres with a drugpolymer ratio of 1:1 was evaluated using a previously described method [23] with some modifications. This test was performed in two mammalian cancer cell lines, MCF-7 (for bone cancer of the mammary organ) and Caco-2 (for mammalian epithelial colorectal 
adenocarcinoma). The mammary gland breast cancer cell line (MCF-7), and human mammalian epithelial colorectal adenocarcinoma (Caco-2) were purchased from the American Type Culture Collection (ATCC \#ATCC ${ }^{\circledR} 30-4500 K^{\mathrm{TM}}$, Middlesex, UK). Cells were grown in Dulbecco's modified Eagle's medium (DMEM) supplemented with $100 \mathrm{U} / \mathrm{mL}$ penicillin and $10 \%$ foetal bovine serum (FBS) to $75-85 \%$ confluency. After incubation, the cells were treated with 1 to $50 \mu \mathrm{M}$ ETO free drug or ET-ETO microparticles and incubated for $24 \mathrm{~h}$. With an ELISA microplate reader (EXL 800 USA), each well's optical (OD) quantity was evaluated at $570 \mathrm{~nm}$. The $50 \%\left(\mathrm{IC}_{50}\right)$ inhibitory level was calculated from an estimated viability curve versus the exact ETO level. Viability was measured as:

(A570 of the administered sample/A570 of the treatable sample) $\times 100$

The $\mathrm{IC}_{50}$ values were calculated with the program SigmaPlot (Systat Software Inc., Berkshire, UK) for each compound. All information was evaluated to assess the impacts of the compounds studied on cell viability and development. Three independent experiments were performed for each concentration [23].

\subsection{Statistical Analysis}

All statistical analyses were performed using one-way analysis of variance (ANOVA). Minitab ${ }^{\circledR} 16$ Statistical Software with Tukey's multiple comparisons test was employed to compare the formulations. Statistically significant differences were assumed when $p<0.05$. All values are expressed as the mean \pm standard deviation $[24,25]$.

\section{Results and Discussion}

3.1. Preparation and Characterization of the Prepared Ethylcellulose Microparticles Loaded with ETO

The main objective of this study was to prepare a microparticle formulation with improved solubility and enhanced release in media at $\mathrm{pH} 7.4$ (suitable duodenal bulb medium). Microparticles composed of EC containing ETO with drug-polymer ratios of $1: 1,1: 3,1: 6$, and 1:20 were prepared with regular sizes and spherical shapes, and the sizes obtained by LPSA are shown in Table 1 . Table 1 shows that the microparticles loaded with ETO and dried by lyophilization had a smaller size than the same formulation dried by oven-drying. The blank lyophilized microparticles had a nano range of $86.1 \pm 0.01 \mathrm{~nm}$ in comparison to the dried microparticles' range of $2300 \pm 1012 \mathrm{~nm}$. Figure $2 \mathrm{a}, \mathrm{b}$ shows the primary dried microparticles prepared at a 1:1 of D/P containing ETO, which had a size of $163 \mu \mathrm{m}$. The freeze-dried microparticles loaded with ETO showed a size of $0.088 \mu \mathrm{m}$; the size was reduced due to lyophilization. Morita et al. showed these same results, with the particle size of BSA decreasing as the PEG-BSA ratio increased due to freezing-induced condensation [26]. Moreover, it was previously reported that freeze-drying can produce smaller particle sizes with relatively large geometric diameters [3].

Table 1. The different sizes of dried ethylcellulose microparticles loaded with etoposide that were prepared and dried by primary or freeze-drying.

\begin{tabular}{ccc}
\hline $\begin{array}{c}\text { Drug to Polymer Ratio } \\
\text { (ETO:EC) Microparticles }\end{array}$ & $\begin{array}{c}\text { Size of Dried (Lyophilized) } \\
\text { ET-ETO MPs }(\mu \mathrm{m})\end{array}$ & $\begin{array}{c}\text { Size of Dried (Primary) } \\
\text { ET-ETO MPs }(\mu \mathrm{m})\end{array}$ \\
\hline blank & $0.086 .1 \pm 0.01$ & $2.3 \pm 1.12$ \\
$1: 1$ & $0.088 \pm 0.001$ & $163.1 \pm 2.3$ \\
$1: 3$ & $1.77 \pm 0.012$ & $189.6 \pm 0.2$ \\
$1: 6$ & $6.33 \pm 0.0 .8$ & $222.1 \pm 12$ \\
$1: 20$ & $91.5 \pm 0.11$ & $234 \pm 2.3$ \\
\hline
\end{tabular}



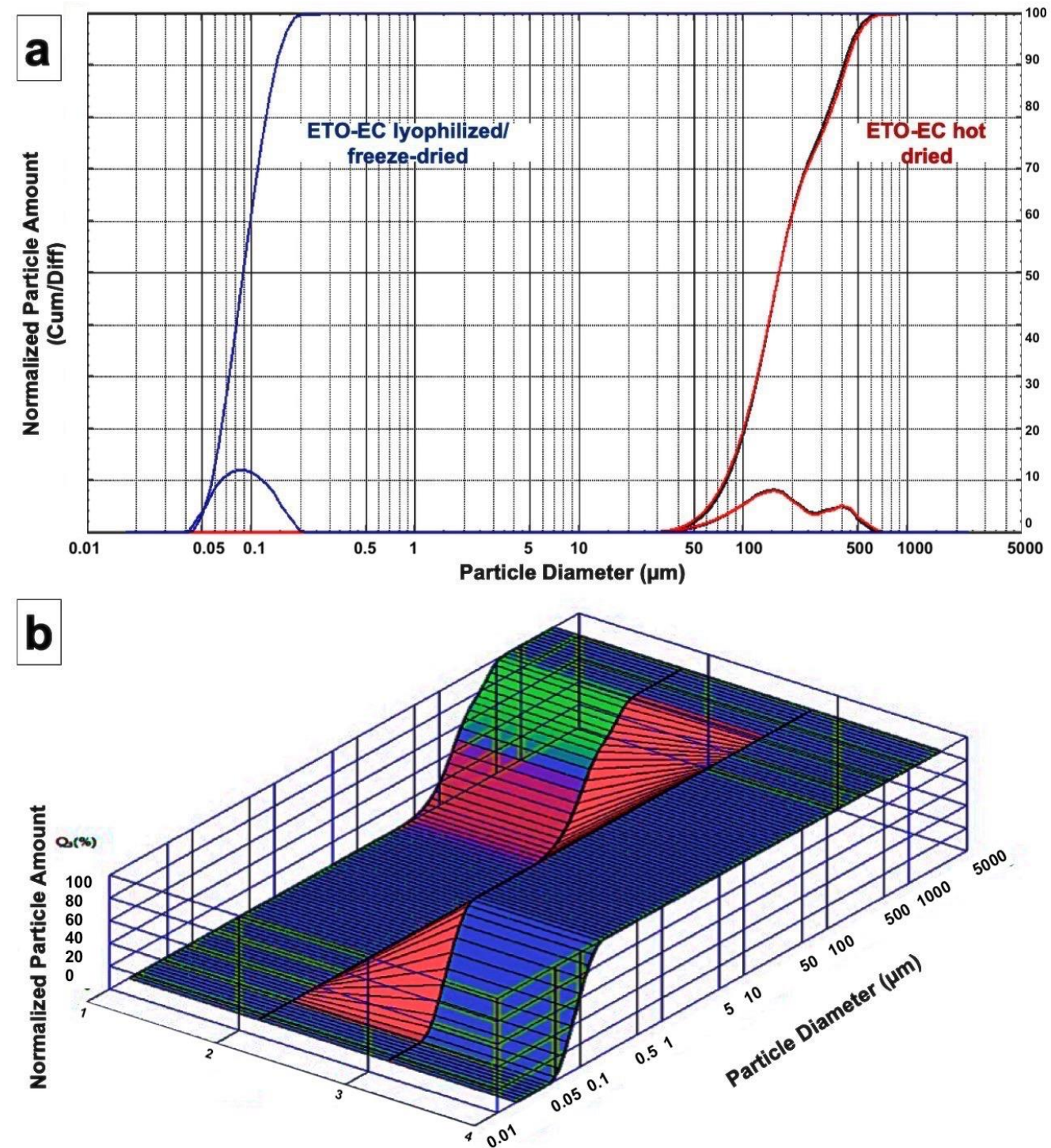

Figure 2. Average size distribution of the prepared ethylcellulose microparticles, blank microparticles (EC-MPs), and loaded etoposide microparticles (ET-ETO-MPs) determined using a particle size analyser: (a) mean particle size distribution and (b) three-dimensional graph of the EC microparticles.

The spherical shape of the prepared microparticles was observed in the photos obtained from scanning electron microscopy (SEM) (Figure 3). The pictures revealed that both the primary dried and freeze-dried samples were spherical (Figure 3a-c). Particularly, the freeze-dried samples vary in morphology and size (Figure 3d) from the primary-dried samples, as they are porous and rough with sticky shill-like shapes (Figure 3e,f). The microparticles maintained their form after freeze-drying, which indicates that freeze-dried microparticles were not affected by the process of lyophilization and were still spherical (Figure 3d-f) $[27,28]$. 

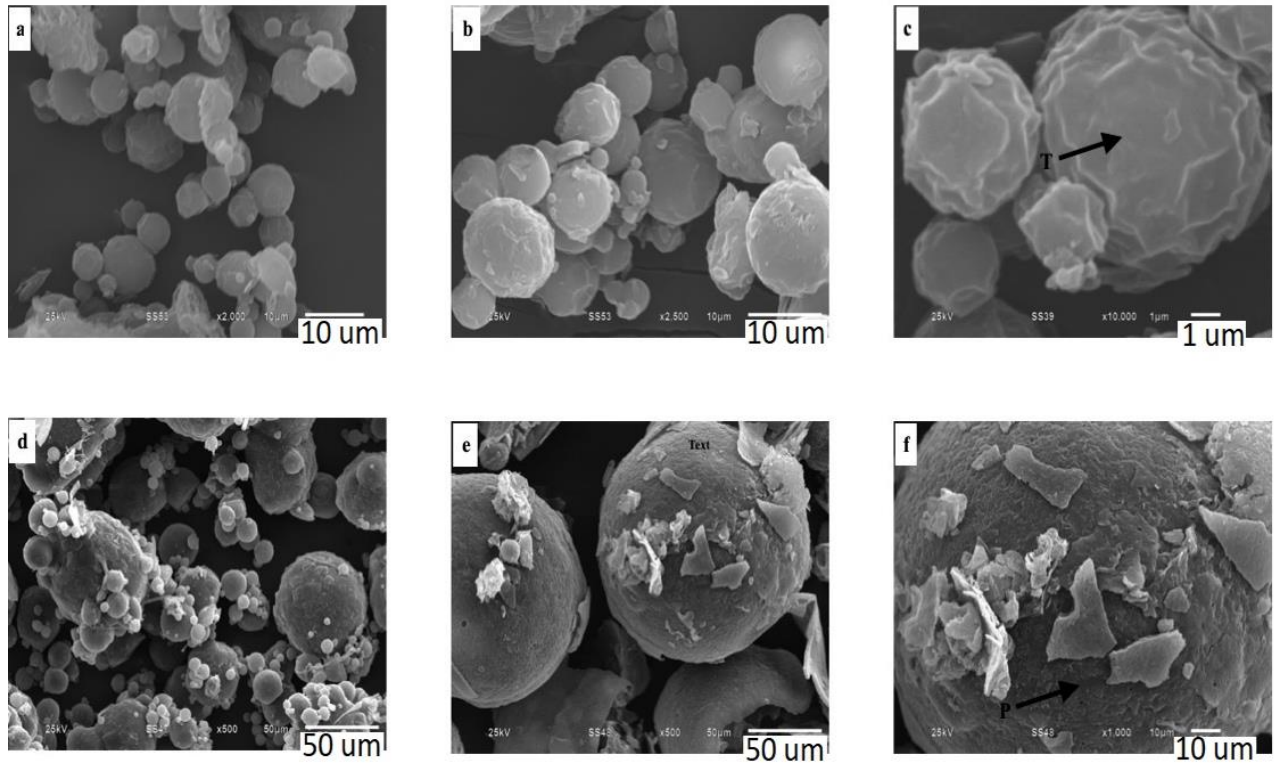

Figure 3. Photos obtained by scanning electron microscopy (SEM) of the ethylcellulose microparticles loaded with and without etoposide. (a) ET-ETO primary-dried $\times 2000$, scale bars $10 \mu \mathrm{m}$. (b) ETETO primary-dried $\times 2500$, scale bars $10 \mu \mathrm{m}$. (c) ET-ETO primary-dried $\times 10,000$, scale bars $1 \mu \mathrm{m}$. (d) ET-ETO freeze-dried $\times 500$, scale bars $50 \mu \mathrm{m}$. (e) ET-ETO freeze-dried $\times 1000$, scale bars $50 \mu \mathrm{m}$. (f) ET-ETO freeze-dried $\times 10,000$, scale bars $10 \mu \mathrm{m}$.

The SEM results agreed with the results obtained from LPSA and confirmed that the size of the ET-ETO microparticles was higher than that of the empty microparticles, as shown in Figure 3. The observed difference in size was due to the difference in shape obtained by SEM. It has also been reported that particle size may increase after freezedrying due to their aggregation $[28,29]$. This also explains the difference in size observed in the SEM images and by LPSA, which confirmed the presence of irregular particle sizes after lyophilization. This finding is in agreement with a previous study which showed that the aggregated particles lead to an increased mean diameter after freeze-drying due to the shrinkage observed for the ET-ETO microparticles [30].

\subsection{Determination of ETO Drug Content in the Ethylcellulose Microparticles}

The results showed that the amount of ETO encapsulated into the microparticles increased as the ratio of polymer decreased. More specifically, the amount encapsulated was 387.3, 365.0, 350.0, and $250 \mu \mathrm{g} / 50 \mathrm{mg}$ microparticles for microparticles with drugpolymer ratios of 1:1,1:3,1:6, and 1:20, respectively (Figure 4). This finding agrees with a previous study reporting that the drug content per milligram of EC microparticles increased as the drug-polymer ratio $(\mathrm{D} / \mathrm{P})$ increased $[31,32]$.

\subsection{Fourier Transform Infrared Spectroscopy (FT-IR)}

Interactions between pharmaceutical substance fields play a crucial role in releasing medications. Figure 5 shows the FT-IR spectra of the ETO, EC, and EC-ETO physical mixture samples. The spectra showed bands at approximately $3435 \mathrm{~cm}^{-1}$ that were due to $\mathrm{O}-\mathrm{H}$ vibrations. Additionally, the ETO spectrum showed bands at $2923 \mathrm{~cm}^{-1}$ due to C-H stretching, at $1770 \mathrm{~cm}^{-1}$ due to $\mathrm{C}=\mathrm{O}$ stretching of an ester bond, at $1615 \mathrm{~cm}^{-1}$ due to $\mathrm{C}=\mathrm{O}$ stretching of a carboxyl methyl, and at $1056 \mathrm{~cm}^{-1}$ due to $\mathrm{C}-\mathrm{O}-\mathrm{C}$ stretching. The spectrum also showed bands at $1487 \mathrm{~cm}^{-1}$ and $1405 \mathrm{~cm}^{-1}$, which match the $C=C$ stretching of the backbone of the ETO aromatic ring. Compared with those of EC and ETO, the spectrum of the physical mixture presented all the obtained characteristic bands of ETO with small shifts, indicating the existence of pure ETO and EC in the mixture of ETO and EC, which remained unchanged. Figure 5 shows the absence of any new peaks in the physical mixture, 
and all characteristic peaks of ETO, EC, and ET-ETO appeared without any significant shift, indicating the absence of chemical drug-polymer interactions in the solid state. Qian et al. and Patel et al. showed the same results for different ETO polymers [33,34]. The physical stability of the prepared microparticles with and without ETO was confirmed by storage of the prepared microparticles for two months at $25^{\circ} \mathrm{C}$ and $4{ }^{\circ} \mathrm{C}$. The results showed no change in colour, shape, particle size diameter, or drug content before and after storage.

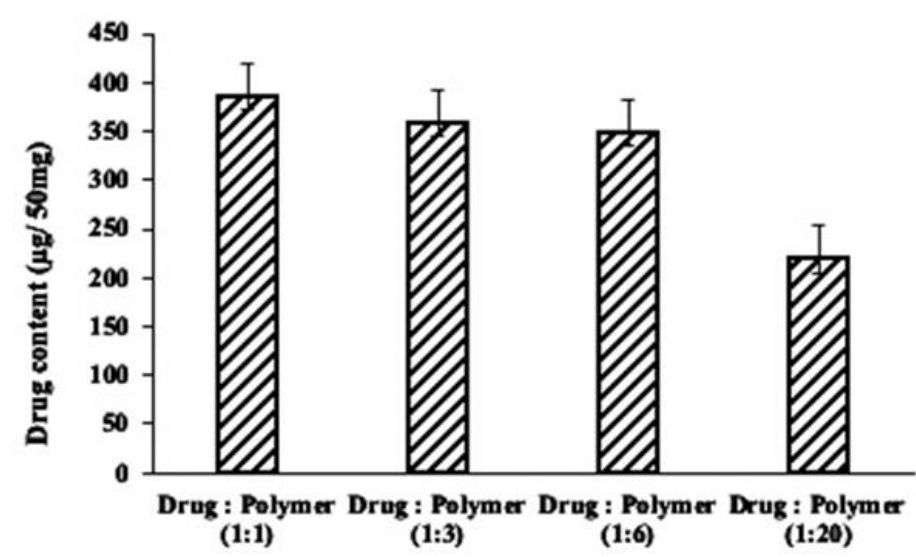

Figure 4. The amount of etoposide encapsulated into $50 \mathrm{mg}$ of ethylcellulose microparticles dried using the freeze-drying technique.

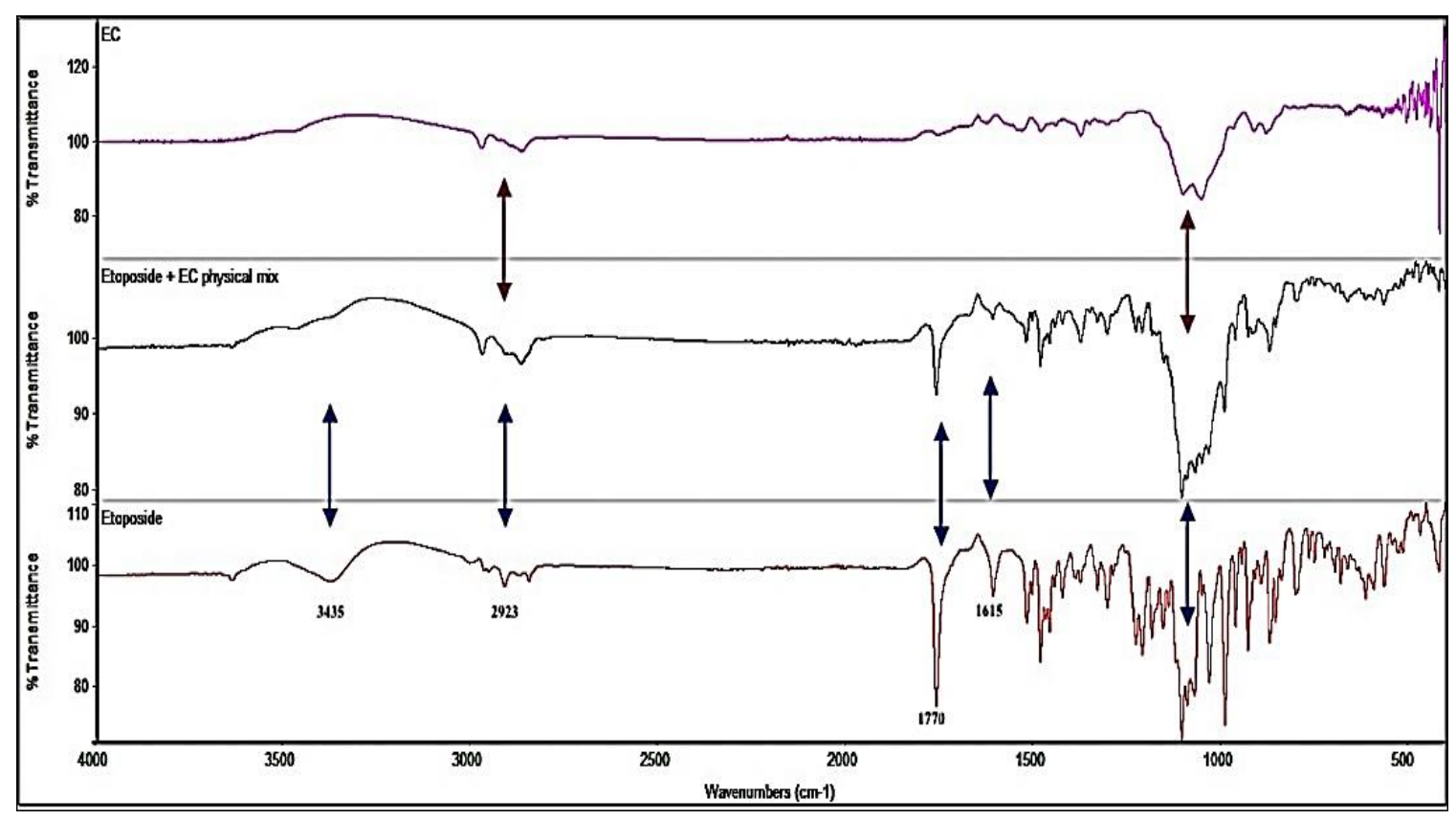

Figure 5. FT-IR spectra of the formulated ethylcellulose-loaded etoposide microparticles. From top to bottom: EC, physical mixture of EC-ETO, and ETO.

\subsection{In Vitro Release Study of the Ethylcellulose Microparticles Loaded with ETO}

The release of ETO from prepared microparticles before and after freeze-drying in $0.1 \mathrm{~N} \mathrm{HCl}$ at $\mathrm{pH} 1.2$ (simulated gastric fluid without enzymes) and in phosphate buffer at pH 7.4 (simulated intestinal fluid without enzymes) was studied. The results showed that the percentage of drug released from the prepared microparticles was highly affected by the $\mathrm{pH}$ of the dissolution medium. The release of ETO from the prepared microparticles without freeze-drying at pH 1.2 (simulated gastric fluid without enzymes) was slow and 
incomplete. More specifically, the percentage of drug released after $1 \mathrm{~h}$ was $24,15,13$, and $0 \%$ for microparticles with drug-polymer ratios of 1:1, 1:3, 1:6, and 1:20, respectively, while after $2 \mathrm{~h}$ (maximum gastric residence time), the percentage of drug released from the same type of microparticles was $49,33,36$, and $24 \%$, respectively. These results match the results reported by Gowda et al., who showed that drug-loaded EC microparticles' burst release at intestinal $\mathrm{pH}$ might be due to the slow and sustained release of the drug that accumulated on the surface of the microparticles. Additionally, the drug and polymer concentrations showed that a decrease in EC concentration assisted in regulating drug release from the microparticles. Furthermore, there was no significant release of drugs at gastric $\mathrm{pH}$, which indicates that the EC polymer is gastro-resistant [35] (Figure 6). Similar release results in simulated gastric and duodenal $\mathrm{pH}$ were also obtained by Yamad et al., who formulated sustained-release ketoprofen microparticles coated with ethylcellulose and carboxymethyl ethylcellulose [36].

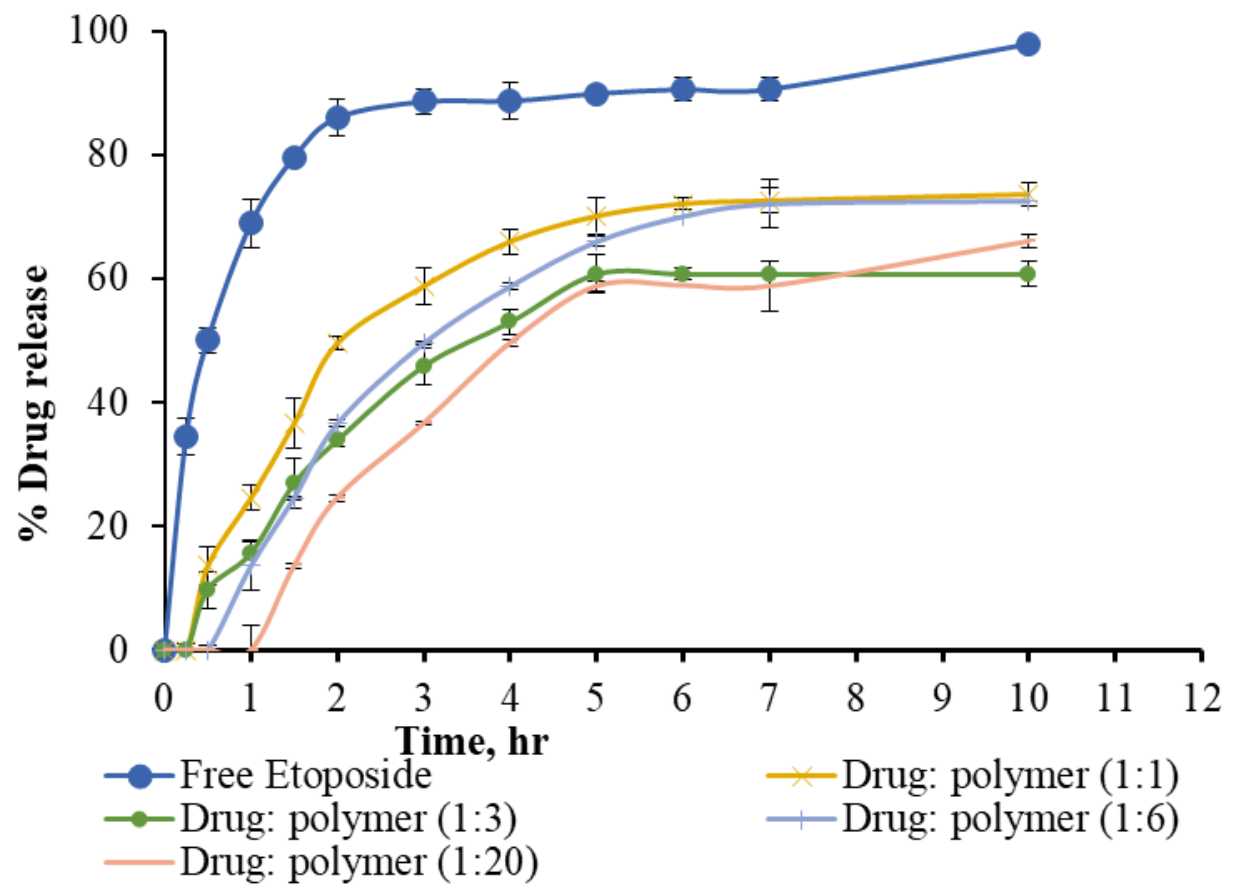

Figure 6. Dissolution profiles at $\mathrm{pH} 7.4$ for free etoposide and the ET-ETO microparticles dried using primary drying at different drug-polymer ratios.

Further, the freeze-dried microparticles were stable in $0.1 \mathrm{~N} \mathrm{HCl}$ (gastric $\mathrm{pH}$ ) for $2 \mathrm{~h}$, as no significant release was recorded. The results of the percentage of ETO released from the prepared microparticles at $\mathrm{pH} 7.4$ before freeze-drying showed that all microsphere formulations controlled and reduced the release rate of ETO in comparison with free ETO. The dissolution data showed that the release of ETO after $10 \mathrm{~h}$ was only 55 to $70 \%$. Figure 7 shows the percentage of ETO released from the freeze-dried microparticles. From the dissolution data in Table 2, it is evident that the freeze-dried microparticles with drug-polymer ratios of 1:1, 1:3, and 1:6 released approximately 60 to $70 \%$ of the ETO within the first $15 \mathrm{~min}$ and approximately $100 \%$ of the ETO within $30 \mathrm{~min}$ at $\mathrm{pH} 7.4$. These results strongly indicate that the use of the freeze-drying technique for the microparticles prepared in this study is a good technique to enhance the solubility of ETO and increase the release rate of ETO at $\mathrm{pH}$ 7.4. This finding is in agreement with the previously mentioned study, where the solubility of ibuprofen was significantly enhanced by using the freeze-drying technique [37]. Similar results were obtained by Wei et al., who showed enhanced dissolution of microparticles loaded with poorly soluble drug nanocrystals: the hydroxypropyl cellulose (HPC) polymer used as a matrix carrier had a low viscosity. This enhancement was due to the spray freeze-dried composite particles, which was attributed to the reduction 
in particle size of the drug [38]. Elgindy et al. showed a similar result for a flutamide (FLT) formulation prepared by incorporating immediate-release lyophilized monophasic dispersions and prolonged-release chitosan microparticles. The established controlled release formulations were found to be successful in offering the prolonged release of FLT over a long period of time after an appropriate initial burst release [39]. The same results were also reported by Kim et al., who formulated budesonide (BDS)/cyclodextrin (CD) complex-loaded and lyophilized microparticles. The dissolution of BDS was enhanced compared to pure BDS and the hydrophilic polymers. Thus, prepared lyophilized microparticles, including drug-CD complexes, can be potential carriers for the more soluble polymer delivery of BDS [40].

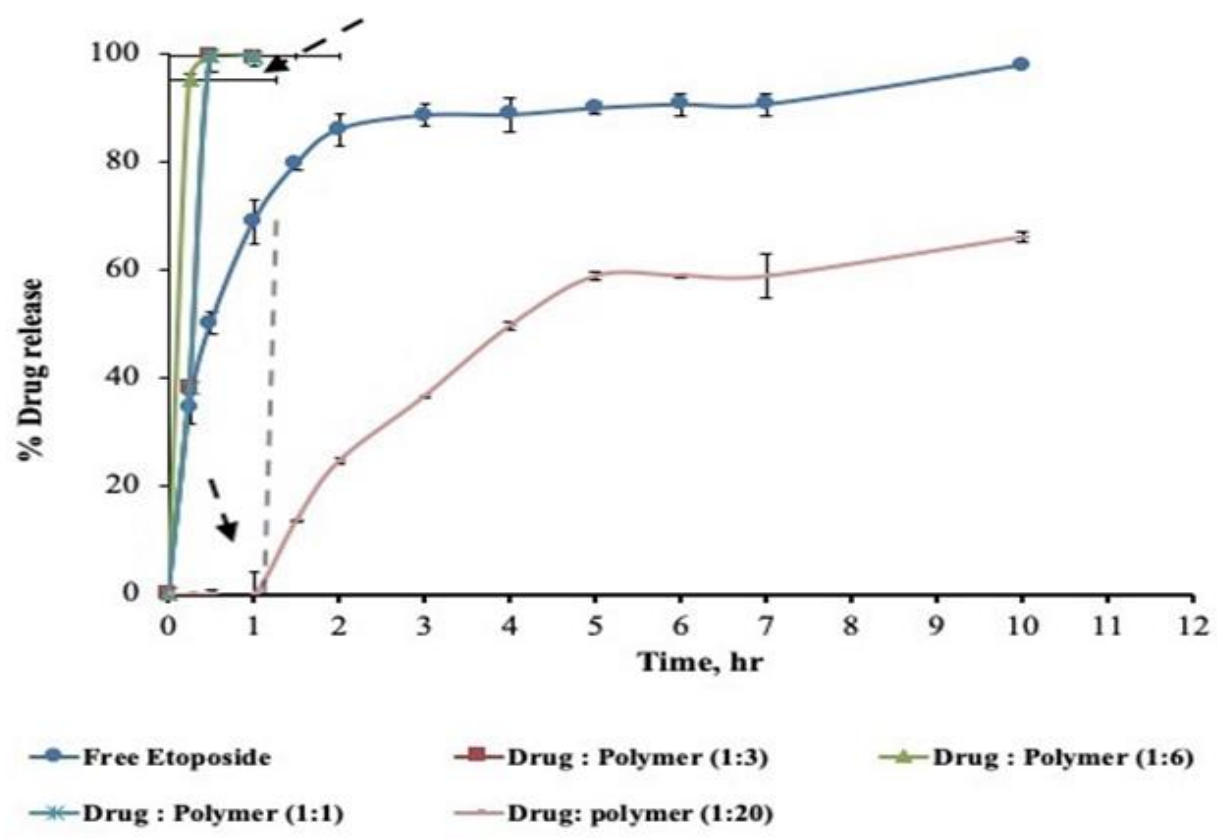

Figure 7. Dissolution profiles at pH 7.4 for free etoposide and freeze-dried ET-ETO microparticles prepared at different drug-polymer ratios.

Table 2. Peppas constants and dissolution rate constants according to the zero-order, first-order, Higuchi, and HixsonCrowell equations.

\begin{tabular}{|c|c|c|c|c|c|}
\hline $\begin{array}{c}\text { Ratio of } \\
\text { Etoposide/ } \\
\text { Ethylcellulose }\end{array}$ & $\begin{array}{c}\text { Zero-Order } \\
\text { Dissolution Rate } \\
\text { Constant }\end{array}$ & $\begin{array}{c}\text { First-Order } \\
\text { Dissolution Rate } \\
\text { Constant }\end{array}$ & $\begin{array}{c}\text { Higuchi } \\
\text { Dissolution Rate } \\
\text { Constant }\end{array}$ & $\begin{array}{c}\text { Hixson-Crowell } \\
\text { Dissolution Rate } \\
\text { Constant }\end{array}$ & Peppas Constant \\
\hline Free drug & $\begin{array}{l}\mathrm{K}=4.76 \\
\mathrm{r}^{2}=0.55\end{array}$ & $\begin{array}{l}\mathrm{K}=0.28 \\
\mathrm{r}^{2}=0.85\end{array}$ & $\begin{array}{l}\mathrm{K}=0.22 \\
\mathrm{r}^{2}=0.87\end{array}$ & $\begin{array}{l}\mathrm{K}=19.8 \\
\mathrm{r}^{2}=0.73\end{array}$ & 0.25 \\
\hline $1: 1$ & $\begin{array}{l}\mathrm{K}=7.23 \\
\mathrm{r}^{2}=0.72\end{array}$ & $\begin{array}{l}\mathrm{K}=0.14 \\
\mathrm{r}^{2}=0.82\end{array}$ & $\begin{array}{l}\mathrm{K}=0.17 \\
\mathrm{r}^{2}=0.95\end{array}$ & $\begin{array}{l}\mathrm{K}=28.9 \\
\mathrm{r}^{2}=0.89\end{array}$ & 0.57 \\
\hline $1: 3$ & $\begin{array}{l}\mathrm{K}=6.43 \\
\mathrm{r}^{2}=0.75\end{array}$ & $\begin{array}{l}\mathrm{K}=0.09 \\
\mathrm{r}^{2}=0.69\end{array}$ & $\begin{array}{l}\mathrm{K}=0.12 \\
\mathrm{r}^{2}=0.87\end{array}$ & $\begin{array}{l}\mathrm{K}=25.5 \\
\mathrm{r}^{2}=0.91\end{array}$ & 0.65 \\
\hline $1: 6$ & $\begin{array}{l}\mathrm{K}=8.30 \\
\mathrm{r}^{2}=0.79\end{array}$ & $\begin{array}{l}\mathrm{K}=0.15 \\
\mathrm{r}^{2}=0.88\end{array}$ & $\begin{array}{l}\mathrm{K}=0.19 \\
\mathrm{r}^{2}=0.97\end{array}$ & $\begin{array}{l}\mathrm{K}=32.4 \\
\mathrm{r}^{2}=0.93\end{array}$ & 0.72 \\
\hline $1: 20$ & $\begin{array}{l}\mathrm{K}=7.91 \\
\mathrm{r}^{2}=0.84\end{array}$ & $\begin{array}{l}\mathrm{K}=0.12 \\
\mathrm{r}^{2}=0.90\end{array}$ & $\begin{array}{l}\mathrm{K}=0.16 \\
\mathrm{r}^{2}=0.95\end{array}$ & $\begin{array}{l}\mathrm{K}=30.2 \\
\mathrm{r}^{2}=0.94\end{array}$ & 0.80 \\
\hline
\end{tabular}

To describe the dissolution kinetics of the prepared microparticles (before freezedrying) at $\mathrm{pH}$ 7.4, five equations were used, namely, the first order, zero order, HixsonCrowell, Higuchi, and Peppas equations. Table 1 shows the best equations that fit the dissolution data for all ET-ETO microparticle formulations used in this study. The results showed that ET-ETO microparticles with drug-polymer ratios of 1:1, 1:6, and 1:20 fit best 
to the Higuchi equation with $\mathrm{r}^{2}$ values equal to $0.95,0.97$, and 0.95 , respectively. The dissolution data for the ET-ETO microparticles with a drug-polymer ratio of 1:3 fit best to the Hixson-Crowell equation, with an $\mathrm{r}^{2}$ value equal to 0.91 . The application of the linear form of the Peppas equation to the dissolution data showed that the dissolution mechanism was Fickian diffusion for free ETO with a Peppas constant $(n)$ less than $0.45(n=0.254)$, as shown in Table 1. Additionally, the results from Table 1 show that the release from all prepared microparticles in this study was non-Fickian transport (anomalous) with Peppas constants (n) equal to $0.57,0.65,0.72$, and 0.80 for microparticles with drug-polymer ratios of 1:1, 1:3, 1:6, and 1:20, respectively. Abdellatif et al. showed the same results for the release kinetics of all formulas for cetuximab-conjugated octreotide loaded with alginate beads. This mechanism was best suited to the Hixson-Crowell equation [14].

\subsection{Cytotoxicity Assay}

An in vitro cytotoxicity assay of free ETO and the freeze-dried microparticles with a drug-polymer ratio of 1:1 was selected for evaluation using a method described previously with some modifications [41]. This test was performed in two mammalian cancer cell types, MCF-7 (bone cancer of the mammary organ) and Caco-2 (mammalian epithelial colorectal adenocarcinoma) (Figure 8). The $\mathrm{IC}_{50}$ values for the free ETO and freeze-dried ET-ETO microparticles were 45.57 and $33.32 \mu \mathrm{M}$ in MCF-7 cells, respectively, while these values were 27.1 and $18.5 \mu \mathrm{M}$ for free ETO and freeze-dried ET-ETO microparticles in Caco-2 cells, respectively. Indeed, the results showed less cytotoxic activity for the freeze-dried ET-ETO microparticles compared to free ETO against both tested cell lines. These results suggest that the ETO coating with EC enhanced the activity of ETO by forming a barrier layer. These findings indicate that EC microparticles loaded with ETO can target a specific area in the gastrointestinal tract at $\mathrm{pH} 7.4$ with potential anticancer activity. Importantly, the activities of the ET-ETO microparticles were synergistic with those of the free drugs, indicating that the anticancer activity was not affected by the EC coating. The main effect detected was that the ideal concentration of ETO could be decreased in the area of colon cancer. At this reduced concentration, the number of live normal cells could increase compared with the high level of dead normal cells that were detected at higher concentrations of free ETO, which makes our formula with a high concentration at the site of action safer.

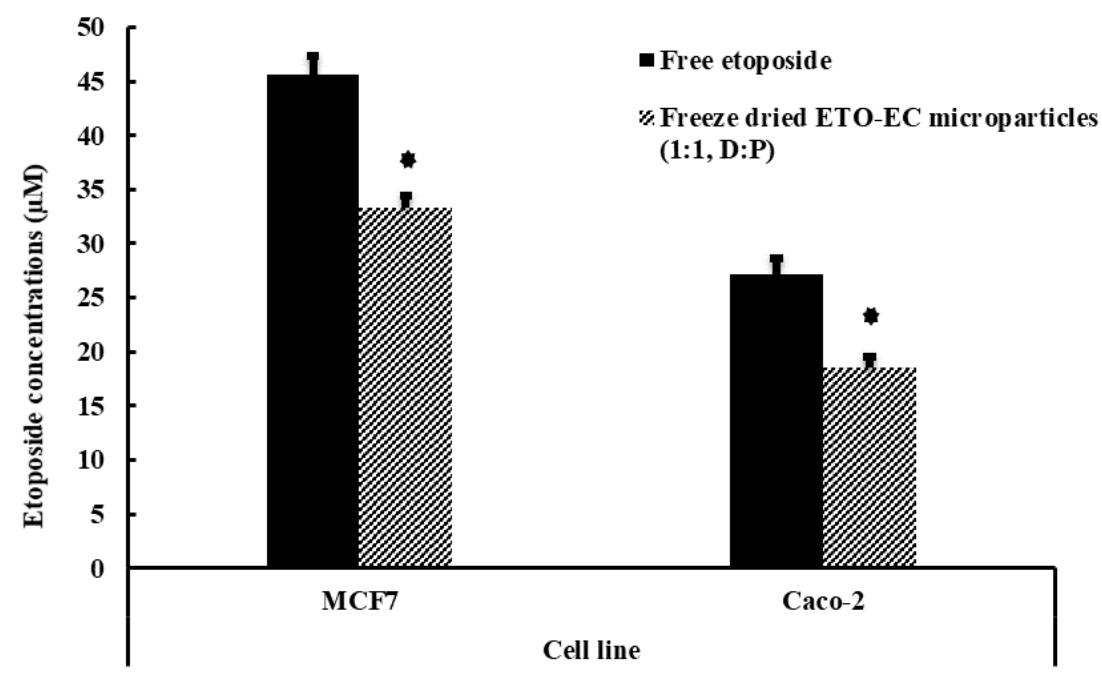

Figure 8. Antiproliferative activity of free etoposide and ET-ETO microparticles at a drug-polymer ratio of 1:1 in MC-7 and Caco-2 cells. * $p$-value less than 0.05 (typically $\leq 0.05$ ) is statistically significant compared with cells treated with free drug.

These results are logical and recommended. It has been reported that the ethylcellulose polymer is toxic to HeLa cells [42]. Ghalaei et al. [43] proved that ETO solid lipid nanoparticles have an $\mathrm{IC}_{50}$ that was reduced to approximately $83 \%$ compared to that of 
the free drug. Additionally, Saliou et al. [44] stated that lipid nanocapsules of ETO lowered the $\mathrm{IC}_{50}$ of ETO from 100 to $2.5 \mu \mathrm{M}$ in $\mathrm{H} 209$ cells, thus reducing the $\mathrm{IC}_{50}$ of ETO to approximately $4-30$-fold that in glioma cell lines [45]. This reduction in $\mathrm{IC}_{50}$, which was also confirmed by Han et al. [46], effectively resolved the drug tolerance of MCF-7 / ADR cells through a 4.3-fold reduction in $\mathrm{IC}_{50}$ using an siRNA polyamidoamine complex. The suggested formulation (freeze-dried ET-ETO microparticles) provides very fast release at $\mathrm{pH} 7.4$ (at the simulated duodenal $\mathrm{pH}$ ) and low cytotoxic activity compared to free ETO against the tested cell lines used in their study. Based on these advantages, our findings are in agreement with those of Asnani et al. [47], who demonstrated that the use of targeted epichlorohydrin crosslinked Portulaca-alginate beads for colon cancer showed an enhancement in the antitumour activity as well as a reduction in the toxicity for some neoplastic drugs.

\section{Conclusions}

The suggested formulation (freeze-dried ET-ETO) offers many advantages, including the following. First, it reduces ETO release in the stomach, which will protect the drug from gastric fluids and reduce the side effects of ETO (nausea and vomiting). Second, it provides very fast release of ETO at $\mathrm{pH} 7.4$ (at the simulated duodenal $\mathrm{pH}$ ) and increases the ETO concentration in the duodenal area. Finally, the freeze-dried ET-ETO microparticles provide significant antiproliferative activity compared to free ETO against the tested cell lines used in this study. Based on these advantages and considering the results obtained in this study, it can be concluded that the use of freeze-dried microparticles containing ETO is a promising formulation that is suitable for ETO targeting of the duodenal area for the local treatment of duodenal cancer.

Author Contributions: Conceptualization, A.A.H.A. and H.M.M.; methodology, A.A.H.A., M.A.A. (Mashari A. Aldhafeeri), W.H.A. (Waleed H. Alharbi), F.H.A. and W.A. (Waleed Almutiri); software, A.A.H.A. and H.M.M.; validation, A.A.H.A. and H.M.M.; formal analysis, A.A.H.A. and H.M.M.; investigation, A.A.H.A., M.A.A. (Mohammed A. Amin), M.F.A. and H.M.M.; resources, A.A.H.A., M.A.A. (Mohammed A. Amin), M.F.A. and H.M.M.; data curation, A.A.H.A., M.A.A. (Mohammed A. Amin), M.F.A. and H.M.M.; writing—original draft preparation, A.A.H.A. and H.M.M.; writingreview and editing, A.A.H.A., M.A.A. (Mohammed A. Amin), M.F.A. and H.M.M.; visualization, A.A.H.A., M.A.A. (Mohammed A. Amin), M.F.A. and H.M.M.; supervision, A.A.H.A. and H.M.M.; project administration, A.A.H.A. and H.M.M.; funding acquisition, M.F.A. All authors have read and agreed to the published version of the manuscript.

Funding: This research received no external funding.

Institutional Review Board Statement: Not applicable.

Informed Consent Statement: Not applicable.

Data Availability Statement: Not applicable.

Acknowledgments: The researchers would like to thank the Deanship of Scientific Research, Qassim University for support of this project.

Conflicts of Interest: The authors declare that there is no conflict of interest.

\section{References}

1. Ziegler, A.; Simon, S.; Lee, G. Comminution of Carbohydrate and Protein Microparticles on Firing in a Ballistic Powder Injector. J. Pharm. Sci. 2010, 99, 4917-4927. [CrossRef] [PubMed]

2. Sonner, C.; Maa, Y.; Lee, G. Spray-freeze-drying for protein powder preparation: Particle characterization and a case study with trypsinogen stability. J. Pharm. Sci. 2002, 91, 2122-2139. [CrossRef] [PubMed]

3. Niwa, T.; Mizutani, D.; Danjo, K. Spray freeze-dried porous microparticles of a poorly water-soluble drug for respiratory delivery. Chem. Pharm. Bull. 2012, 60, 870-876. [CrossRef] [PubMed]

4. Ungaro, F.; Giovino, C.; Coletta, C.; Sorrentino, R.; Miro, A.; Quaglia, F. Engineering gas-foamed large porous particles for efficient local delivery of macromolecules to the lung. Eur. J. Pharm. Sci. 2010, 41, 60-70. [CrossRef]

5. Moghaddam, S.P.H.; Farhat, S.; Vatanara, A. Porous Microparticles Containing Raloxifene Hydrochloride Tailored by Spray Freeze Drying for Solubility Enhancement. Adv. Pharm. Bull. 2018, 8, 217-223. [CrossRef] [PubMed] 
6. Nogueira, G.F.; Fakhouri, F.M.; Velasco, J.I.; De Oliveira, R.A. Active Edible Films Based on Arrowroot Starch with Microparticles of Blackberry Pulp Obtained by Freeze-Drying for Food Packaging. Polymers 2019, 11, 1382. [CrossRef] [PubMed]

7. Cherng, J.; Van De Wetering, P.; Talsma, H.; Crommelin, D.J.A.; Hennink, W.E. Freeze-drying of poly((2-dimethylamino)ethyl methacrylate)-based gene delivery systems. Pharm. Res. 1997, 14, 1838-1841. [CrossRef]

8. Mohammed, H.A.; Al-Omar, M.S.; El-Readi, M.Z.; Alhowail, A.H.; Aldubayan, M.A.; Abdellatif, A.A.H. Formulation of Ethyl Cellulose Microparticles Incorporated Pheophytin A Isolated from Suaeda vermiculata for Antioxidant and Cytotoxic Activities. Molecules 2019, 24, 1501. [CrossRef]

9. Tawfeek, H.M.; Abdellatif, A.A.H.; Dennison, T.J.; Mohammed, A.R.; Sadiq, Y.; Saleem, I.Y. Colonic delivery of indometacin loaded PGA-co-PDL microparticles coated with Eudragit L100-55 from fast disintegrating tablets. Int. J. Pharm. 2017, 531, 80-89. [CrossRef]

10. Leuner, C. Improving drug solubility for oral delivery using solid dispersions. Eur. J. Pharm. Biopharm. 2000, 50, 47-60. [CrossRef]

11. Hung, C.-H.; Wiest, L.A.; Singh, B.; Diwan, A.; Valentim, M.J.C.; Christensen, J.M.; Davis, R.C.; Miles, A.J.; Jensen, D.S.; Vail, M.A.; et al. Improved efficiency of reversed-phase carbon/nanodiamond/polymer core-shell particles for HPLC using carbonized poly(divinylbenzene) microspheres as the core materials. J. Sep. Sci. 2013, 36, 3821-3829. [CrossRef] [PubMed]

12. Wagner, K.; Bodmeier, R. Improvement of the Low-Temperature Stability of an Aqueous Colloidal Ethylcellulose Dispersion, Aquacoat ${ }^{\circledR}$ ECD, and Preparation/Characterization of a Redispersible Aquacoat ${ }^{\circledR}$ ECD Powder. Drug Dev. Ind. Pharm. 2003, 29, 267-275. [CrossRef] [PubMed]

13. Patel, N.; Lalwani, D.; Gollmer, S.; Injeti, E.; Sari, Y.; Nesamony, J. Development and evaluation of a calcium alginate based oral ceftriaxone sodium formulation. Prog. Biomater. 2016, 5, 117-133. [CrossRef] [PubMed]

14. Abdellatif, A.A.H.; Ibrahim, M.A.; Amin, M.A.; Maswadeh, H.; Alwehaibi, M.N.; Al-Harbi, S.N.; Alharbi, Z.A.; Mohammed, H.A.; Mehany, A.B.M.; Saleem, I. Cetuximab Conjugated with Octreotide and Entrapped Calcium Alginate-beads for Targeting Somatostatin Receptors. Sci. Rep. 2020, 10, 4736. [CrossRef]

15. Aly, U.F.; Aboutaleb, H.A.; Abdellatif, A.A.; Tolba, N.S. Formulation and evaluation of simvastatin polymeric nanoparticles loaded in hydrogel for optimum wound healing purpose. Drug Des. Dev. Ther. 2019, 2019, 1567-1580. [CrossRef]

16. Tawfeek, H.M.; Roberts, M.; El Hamd, M.A.; Abdellatif, A.A.H.; Younis, M.A. Glibenclamide Mini-tablets with an Enhanced Pharmacokinetic and Pharmacodynamic Performance. AAPS PharmSciTech 2018, 19, 2948-2960. [CrossRef]

17. Badia, A.; Cuccia, L.; Demers, L.; Morin, F.; Lennox, R.B. Structure and Dynamics in Alkanethiolate Monolayers Self-Assembled on Gold Nanoparticles: A DSC, FT-IR, and Deuterium NMR Study. J. Am. Chem. Soc. 1997, 119, 2682-2692. [CrossRef]

18. Dassenoy, F.; Philippot, K.; Ely, T.O.; Amiens, C.; Lecante, P.; Snoeck, E.; Mosset, A.; Casanove, M.-J.; Chaudret, B. Platinum nanoparticles stabilized by CO and octanethiol ligands or polymers: FT-IR, NMR, HREM and WAXS studies. New J. Chem. 1998, 22, 703-712. [CrossRef]

19. Devlin, J.P.; Buch, V. FT-IR Spectra of Nanoparticles: Surface and Adsorbate Modes. Prog. Fourier Transform. Spectrosc. 1997, 57-66. [CrossRef]

20. Díaz-Visurraga, J.; Daza, C.; Valenzuela, C.P.; Becerra, A.; Cancino, A.G.; von Plessing, C. Study on antibacterial alginate-stabilized copper nanoparticles by FT-IR and 2D-IR correlation spectroscopy. Int. J. Nanomed. 2012, 7, 3597-3612. [CrossRef] [PubMed]

21. Juárez, R.; Parker, S.; Concepción, P.; Corma, A.; García, H. Heterolytic and heterotopic dissociation of hydrogen on ceriasupported gold nanoparticles. Combined inelastic neutron scattering and FT-IR spectroscopic study on the nature and reactivity of surface hydrogen species. Chem. Sci. 2010, 1, 731-738. [CrossRef]

22. Onuki, Y.; Machida, Y.; Yokawa, T.; Seike, C.; Sakurai, S.; Takayama, K. Magnetic Resonance Imaging Study on the Physical Stability of Menthol and Diphenhydramine Cream for the Treatment of Chronic Kidney Disease-Associated Pruritus. Chem. Pharm. Bull. 2015, 63, 457-462. [CrossRef] [PubMed]

23. Bakr, R.B.; Mehany, A.B.M.; Abdellatif, K.R.A. Synthesis, EGFR Inhibition and Anti-cancer Activity of New 3,6-dimethyl-1phenyl-4-(substituted-methoxy)pyrazolo[3,4-d] pyrimidine Derivatives. Anti-Cancer Agents Med. Chem. 2017, 17, 1389-1400. [CrossRef] [PubMed]

24. Abdellatif, A.A.H.; Zayed, G.; Elbakry, A.; Zaky, A.; Saleem, I.Y.; Tawfeek, H.M. Novel gold nanoparticles coated with somatostatin as a potential delivery system for targeting somatostatin receptors. Drug Dev. Ind. Pharm. 2016, 42, 1782-1791. [CrossRef] [PubMed]

25. Abdellatif, A.A.H.; Abou-Taleb, H.A.; El Ghany, A.A.A.; Lutz, I.; Bouazzaoui, A. Targeting of somatostatin receptors expressed in blood cells using quantum dots coated with vapreotide. Saudi Pharm. J. 2018, 26, 1162-1169. [CrossRef]

26. Morita, T.; Horikiri, Y.; Yamahara, H.; Suzuki, T.; Yoshino, H. Formation and isolation of spherical fine protein microparticles through lyophilization of protein-poly(ethylene glycol) aqueous mixture. Pharm. Res. 2000, 17, 1367-1373. [CrossRef]

27. Seyfoddin, A.; Al-Kassas, R. Development of solid lipid nanoparticles and nanostructured lipid carriers for improving ocular delivery of acyclovir. Drug Dev. Ind. Pharm. 2013, 39, 508-519. [CrossRef]

28. Müller, R.H.; Mäder, K.; Gohla, S. Solid lipid nanoparticles (SLN) for controlled drug delivery â $€^{\prime \prime}$ a review of the state of the art. Eur. J. Pharm. Biopharm. 2000, 50, 161-177. [CrossRef]

29. Mehnert, W.; Mäder, K. Solid lipid nanoparticles Production, characterization and applications. Adv. Drug Deliv. Rev. 2001, 47, 165-196. [CrossRef]

30. Straller, G.; Lee, G. Shrinkage of spray-freeze-dried microparticles of pure protein for ballistic injection by manipulation of freeze-drying cycle. Int. J. Pharm. 2017, 532, 444-449. [CrossRef] 
31. Mastiholimath, V.S.; Dandagi, P.M.; Gadad, A.; Mathews, R.; Kulkarni, A.R. In vitro and in vivo evaluation of ranitidine hydrochloride ethyl cellulose floating microparticles. J. Microencapsul. 2008, 25, 307-314. [CrossRef]

32. Arici, M.; Topbas, O.; Karavana, S.Y.; Ertan, G.; Sariişik, M.; Öztürk, C. Preparation of naproxen-ethyl cellulose microparticles by spray-drying technique and their application to textile materials. J. Microencapsul. 2014, 31, 654-666. [CrossRef] [PubMed]

33. Wang, S.-L.; Sun, D.-M.; Zhu, R.-R.; Du, X.-L.; Liu, H.; Qian, W.-Y. pH-sensitive strontium carbonate nanoparticles as new anticancer vehicles for controlled etoposide release. Int. J. Nanomed. 2012, 7, 5781-5792. [CrossRef] [PubMed]

34. Patel, D.M.; Patel, C.N.; Jani, R.H. Design and evaluation of colon targeted modified pulsincap delivery of 5-fluorouracil according to circadian rhythm. Int. J. Pharm. Investig. 2011, 1, 172-181. [CrossRef] [PubMed]

35. Gowda, D.; Gowrav, M.; Gangadharappa, H.; Khan, M. Preparation and Evaluation of Mixture of Eudragit and Ethylcellulose Microparticles Loaded with Ranolazine for Controlled Release. J. Young-Pharm. 2011, 3, 189-196. [CrossRef] [PubMed]

36. Yamada, T.; Onishi, H.; Machida, Y. Sustained release ketoprofen microparticles with ethylcellulose and carboxymethylethylcellulose. J. Control. Release 2001, 75, 271-282. [CrossRef]

37. Preskar, M.; Vrbanec, T.; Vrečer, F.; Šket, P.; Plavec, J.; Gašperlin, M. Solubilization of ibuprofen for freeze dried parenteral dosage forms. Acta Pharm. 2019, 69, 17-32. [CrossRef]

38. Wei, S.; Ma, Y.; Luo, J.; He, X.; Yue, P.; Guan, Z.; Yang, M. Hydroxypropylcellulose as matrix carrier for novel cage-like microparticles prepared by spray-freeze-drying technology. Carbohydr. Polym. 2017, 157, 953-961. [CrossRef]

39. Elgindy, N.; Elkhodairy, K.; Molokhia, A.; Elzoghby, A. Biopolymeric microparticles combined with lyophilized monophase dispersions for controlled flutamide release. Int. J. Pharm. 2011, 411, 113-120. [CrossRef]

40. Kim, J.-E.; Cho, H.-J.; Kim, D.-D. Budesonide/cyclodextrin complex-loaded lyophilized microparticles for intranasal application. Drug Dev. Ind. Pharm. 2013, 40, 743-748. [CrossRef]

41. Li, F.; Liu, D.; Liao, X.; Zhao, Y.; Li, R.; Yang, B. Acid-controlled release complexes of podophyllotoxin and etoposide with acyclic cucurbit[n] urils for low cytotoxicity. Bioorganic Med. Chem. 2019, 27, 525-532. [CrossRef]

42. Calejo, M.T.; Cardoso, A.; Marques, E.F.; Araújo, M.J.; Kjøniksen, A.-L.; Sande, S.A.; de Lima, M.C.P.; Jurado, A.S.; Nyström, B. In vitro cytotoxicity of a thermoresponsive gel system combining ethyl(hydroxyethyl) cellulose and lysine-based surfactants. Colloids Surf. B Biointerfaces 2013, 102, 682-686. [CrossRef]

43. Ghalaei, P.M.; Varshosaz, J.; Aliabadi, H.S. Evaluating Cytotoxicity of Hyaluronate Targeted Solid Lipid Nanoparticles of Etoposide on SK-OV-3 Cells. J. Drug Deliv. 2014, 2014, 1-7. [CrossRef]

44. Saliou, B.; Thomas, O.; Lautram, N.; Clavreul, A.; Hureaux, J.; Urban, T.; Benoit, J.-P.; Lagarce, F. Development and in vitro evaluation of a novel lipid nanocapsule formulation of etoposide. Eur. J. Pharm. Sci. 2013, 50, 172-180. [CrossRef] [PubMed]

45. Lamprecht, A.; Benoit, J.-P. Etoposide nanocarriers suppress glioma cell growth by intracellular drug delivery and simultaneous P-glycoprotein inhibition. J. Control. Release 2006, 112, 208-213. [CrossRef] [PubMed]

46. Han, M.; Lv, Q.; Tang, X.-J.; Hu, Y.-L.; Xu, D.-H.; Li, F.-Z.; Liang, W.-Q.; Gao, J.-Q. Overcoming drug resistance of MCF-7/ADR cells by altering intracellular distribution of doxorubicin via MVP knockdown with a novel siRNA polyamidoamine-hyaluronic acid complex. J. Control. Release 2012, 163, 136-144. [CrossRef] [PubMed]

47. Asnani, G.P.; Kokare, C.R. In vitro and in vivo evaluation of colon cancer targeted epichlorohydrin crosslinked Portulaca-alginate beads. Biomol. Concepts 2018, 9, 190-199. [CrossRef] [PubMed] 